\title{
THEORETICAL ANALYSIS AND EXPERIMENTAL STUDY ON THE PROCESS OF CONVEYING AGRICULTURAL FIBER MATERIALS BY SCREW CONVEYORS
}

\author{
Wulantuya $^{1}$, Hongbo Wang${ }^{1}$, Chunguang Wang ${ }^{*}$, Qinglin ${ }^{1}$
}

\author{
${ }^{1 *}$ Corresponding author. Inner Mongolia Agricultural University/ Hohhot, China. \\ E-mail: jdwcg@imau.edu.cn | ORCID ID: https://orcid.org/0000-0001-6709-3422
}

\section{KEYWORDS}

coarse fodder, experimental study, theoretical analysis, screw conveyor.

\begin{abstract}
To improve the conveying efficiency and working stability of a screw conveyor, the feeding methods, running conditions and flow characteristics of materials were studied by theoretical analysis and experiments. The theoretical analysis results show that the screw conveyor runs more stably when the helix angle of the screw blade is equal to the moving helical angle. A new spring-finger was designed by us and was used in the experiment. The experimental results show prove that the spring-finger feeder can help homogeneously and continuously to feed the screw conveyor and to improve the working stability of the screw conveyor. The movement state of materials along a pitch was videotaped by a high-speed camera with different filling rates and rotation speeds. The photographs and videos reveal that the characteristics of the materials and rotational speed affect the conveying performance and provide the basis for selecting the best operating parameters for screw conveyors.
\end{abstract}

\section{INTRODUCTION}

China produces large quantities of crop straws and is focused on turning them into fertilizer, fuel, forage, energy usage and industrialization (Tian et al., 2011; Chu et al., 2016; Song et al., 2017; Ma et al., 2018). The screw conveyor is a necessary equipment to collect, store and process crop straws. Therefore, the study on the conveying of the coarse fodder by the screw conveyor is important to the processing of crop straws.

The technology of the screw conveyor is quite mature in northern Europe. Denmark has the most advanced technology, and its products are widely used in Europe; however, the theoretical analysis on the screw conveyor is rarely reported (Rorres et al., 2000; Alma et al., 2005; Owen \& Cleary, 2009; Wang et al., 2017). In China, the use of the screw conveyor to feed, convey and elevate materials has approximately 100 years of history. However, its usage to convey agricultural fiber material has only recently drawn people's attention. In the machinery industry for harvesting and processing agricultural fiber materials, there is an accuracy requirement for the weight and homogeneity of the materials, and working stability is required in the conveying process. Researchers in China have performed related studies. Huang Shimao (Huang et al., 2000) has studied the congestion problems when grass fiber materials are delivered into a screw conveyor; by changing the shape of the feeding throat, he solved the congestion problem, which reduced the power consumption; however, the homogeneity problem of feeding materials was not solved. Bai Xiaohu and Zhang Xiuli (Bai et al., 2007; Zhang et al., 2018), along with their teams, developed a screw conveyor to bulk and tested that the screw conveyor could qualify the conveying requirement of crop straws with granularity of $2 \mathrm{~mm}$ to 10 $\mathrm{mm}$ and different moisture contents.

According to the relevant documents, the fragment straw material is mainly viewed as coarse particles of a wide range of distribution. The study on chopped straw materials mainly focuses on supposing the materials are powder to study the characteristics of motion. The rubbing process of straw materials is a processing technology that dates back to the 1980s in China. Especially in agricultural engineering, the application of rubbed straw has drawn more attention because of its advantages, and the relevant conveying instruments have been developed. The rubbed corn materials in this study consist of the straw bark, corn-cob and leaves, which belong to a flexible body group with irregular shape, flexibility and bending characteristics. In addition, the body group has complex force, anisotropy and poor mobility. These characteristics make the conveying difficult to study

${ }^{1}$ Inner Mongolia Agricultural University/ Hohhot, China.

Wulantuya and Hongbo Wang contribute equally to this work

Area Editor: Murilo Aparecido Voltarelli

Received in: 9-27-2019

Accepted in: 7-6-2020 
and restrict the development of the screw conveyor device in the forage industry.

A test-bed of the screw conveyor device was developed based on the conveying characteristics of the screw conveyor. The movement of its helical blade and the theory of the flow of rubbed corn straw were analyzed, and an experiment was done on its conveying performance.

\section{STRUCTURAL PARAMETER AND WORKING MECHANISM}

\section{Determination of the structural parameter}

As shown in Figure 1, the screw conveyor consists of a motor (Model: 5M120GU-C; Working voltage: AC $220 \mathrm{~V}$; Rated speed: $1350 \mathrm{r} / \mathrm{min}$ ), elastic coupling, a JN338 intelligent digital torque, a rotational speed measurer (Torque accuracy: $\leq 0.2 \% \mathrm{~F} \cdot \mathrm{S}$; Linear: $\leq 0.1 \% \mathrm{~F} \cdot \mathrm{S}$; Working temperature: $-20 \sim 60^{\circ} \mathrm{C}$ ), storage hopper, spiral casing, screw shaft and frame. The conveying length was $2500 \mathrm{~mm}$, the diameter and pitch of the screw were $250 \mathrm{~mm}$, the diameter of the center shaft was $60 \mathrm{~mm}$, and the clearance between the helical blade and the case of the machine was 5-8 $\mathrm{mm}$.

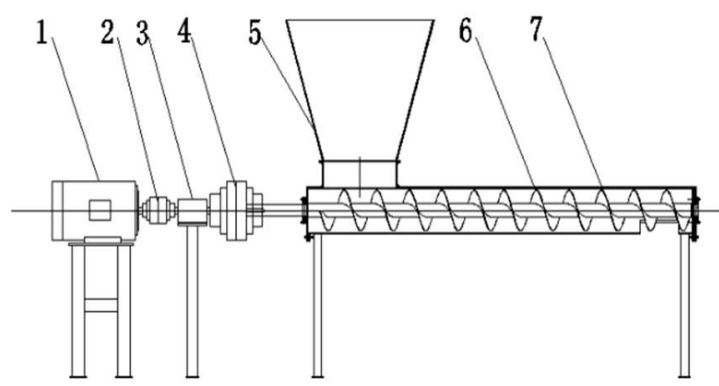

FIGURE. 1 Diagram of the test-bed of screw conveyor. 1-motor; 2-couplings; 3 -the measuring instrument of speed and torque; 4-couplings; 5 -hopper; 6-outer casing; 7-screw axis

\section{Working mechanism}

We use rubbed corn straw as the particle material with a large range of size distribution (Feng et al., 2015). According to Coulomb's law, shear stress $\tau$ is proportional to normal stress $\sigma$ when the straw particles begin to slip.

$$
\begin{aligned}
& \tau=\mu \sigma+\mathrm{c} \\
& \mu=\tan \varphi
\end{aligned}
$$

Where:

$\mu$ is the friction coefficient between straw materials;

c is the initial tensile strength, and

$\varphi$ is the internal friction angle of the straw particle.

The friction among straw, surface of the casing and shafts follows Coulomb's law.

$$
\mu=\tan \varphi_{0}
$$

Where:

$\varphi_{0}$ is the friction angle between the straw and the surface of the casing or screw blade.
According to the above analysis, the working process of the screw conveyor is as follows: the screw shaft is driven by the motor, whose speed is governed by the CNT800-4 t0075G multifunction digital frequency converter. The materials are fed into the machine through the feeding hopper. With gravity and the push of the helical blade, the materials are relatively displaced by the friction among themselves, between materials and surface of the casing and between materials and screw blade. When the shear stress on some straw is $\tau<\mu \sigma+\mathrm{c}$, the straw will stick to the helical blade and move circumferentially. When $\tau=\mu \sigma+\mathrm{c}$, the straw will move axially, so the material is conveyed.

\section{ANALYSIS OF THE MOVEMENT OF THE HELICAL BLADE}

\section{Determination of the coordinates of motion of the helical blade}

We use Cartesian coordinate system to perform the three-dimensional motion of the helical blade as shown in Figure 2. The helical blade rotates in dimension (yoz), whose direction of principal axis is the $x$-axis. Set (oxyz) for the static coordinate system and $\left(o^{\prime} x^{\prime} y^{\prime} z^{\prime}\right)$ for the moving coordinate system, as shown in Figure 3.

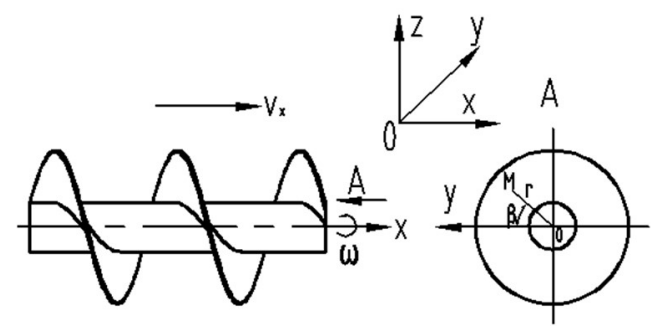

FIGURE. 2 Diagram of the movement of helical blade.

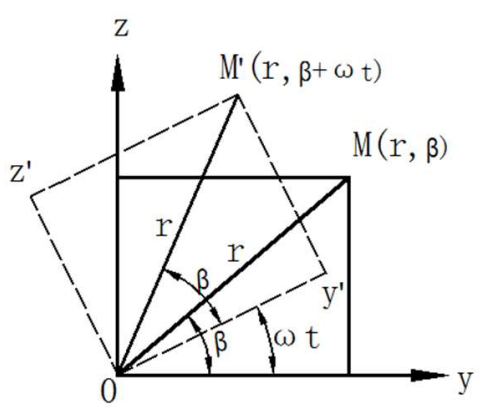

FIGURE 3. Diagram of the change of the coordinates of the motion of point $\mathrm{M}$.

\section{Analysis on the movement of the helical blade}

Suppose that: (1) the test-bed of screw conveyor runs stably; (2) the actual running speed of the helical blade on the $\mathrm{x}$-axis is $\mathrm{V}_{x}(\mathrm{~m} / \mathrm{s})$, the rotational speed is $\mathrm{n}(\mathrm{r} / \mathrm{min})$ $(\omega=2 \pi \mathrm{n})$, the pitch of the helical blade is $\mathrm{S}$, and the diameter of center shaft is $\mathrm{d}$; (3) the helical blade consists of infinite micro circles of different diameters. Choose point $M(\mathrm{r}, \beta)$ on any diameter of the helical blade; then, the equation of the moving coordinate system $\left(o^{\prime} x^{\prime} y^{\prime} z^{\prime}\right)$ of $M$ is: 


$$
\left\{\begin{array}{l}
\mathrm{x}_{M}=\frac{\beta S}{2 \pi} \\
y_{M}=r \cos \beta \\
z_{M}=r \sin \beta
\end{array}\right.
$$

Where:

$\beta$ is the angle between the radius where $\mathrm{M}$ belongs and the y-axis;

$r$ is the radius of the circle where $\mathrm{M}$ belongs;

$\mathrm{x}_{\mathrm{M}}, \mathrm{y}_{M}, \mathrm{z}_{M}$ are the displacements in the $\mathrm{x}, \mathrm{y}$ and $\mathrm{z}$ directions, respectively. The equation of the displacement of point $\mathrm{M}$ in the static coordinate system and the velocity and acceleration are as follows:

$\left\{\begin{array}{l}\mathrm{x}=v_{x} t+\frac{S \beta}{2 \pi} \\ y=r \cos (\beta+\omega t) \\ z=r \sin (\beta+\omega t)\end{array}\right.$

$\left\{\begin{array}{l}x=v_{x} \\ y=-r \omega \sin (\beta+\omega t) \\ z=r \omega \cos (\beta+\omega t)\end{array}\right.$

$\left\{\begin{array}{l}\ddot{x}=0 \\ \ddot{y}=-r \omega^{2} \cos (\beta+\omega t) \\ \ddot{z}=-r \omega^{2} \sin (\beta+\omega t)\end{array}\right.$

Where:

$\mathrm{x}, \mathrm{y}, z$ are the velocities of point $\mathrm{M}$ in the $\mathrm{x}, y, z$ directions, respectively; $\mathrm{x}, \mathrm{y}, \mathrm{z}$ are the accelerations of point $\mathrm{M}$ in the $\mathrm{x}, y, z$ directions, respectively; and $\omega$ is the angular velocity of turning of the helical blade.

$$
\begin{aligned}
\mathrm{v}_{M} & =\sqrt{\dot{x^{2}+y^{2}+z^{2}}}=\sqrt{\mathrm{v}_{x}^{2}+\left[-\omega^{2} r^{2} \sin (\beta+\omega t)\right]+\left[\omega^{2} r^{2} \cos (\beta+\omega t)\right]} \\
& =\sqrt{v_{x}^{2}+\omega^{2} r^{2}}
\end{aligned}
$$

Where:

$\mathrm{V}_{M}$ is the absolute velocity of point $\mathrm{M}$. The axial speed of the screw is $\mathrm{v}_{x}=\frac{\omega S}{2 \pi}$. Substituting it into [eq. (5)], we obtain:

$$
\mathrm{v}_{M}=\omega \sqrt{\frac{S^{2}}{4 \pi^{2}}+r^{2}}
$$

\section{ANALYSIS OF THE INFLUENTIAL FACTORS ON} CONVEYING AND THE RELATED STUDY

\section{Evaluating indices of conveying}

From the previous study on the performance of the screw conveyor, it is obvious that the screw conveyor should have high efficiency and stable conveying capability. The condition of stable conveying is that the movement of materials inside the screw conveyor is mainly treated as axial movement, the additional material flow is vertical to the conveying direction, and the roll of materials is minor. The conveying stability of the screw conveyor mainly reflects that the conveyor can stably run, the filling rate of materials inside the screw conveyor is stable and homogeneous, and the feeding amount per unit time is stable. One of the indices of the conveying efficiency is the utilization ratio of speed of the helical blade. There is no relative motion between materials and helical blade. When the speed of the axial advance is equal to the speed of advance of the helical blade, the conveyor shows the highest efficiency (Wulantuya et al., 2015; Wulantuya et al., 2016).

Effect of the running stability of the test-bed on the conveying stability

The stability of the test-bed of the screw conveyor is basic for the stable conveying of materials inside. Set the pitch angle of the diameter of the micro circle where point $\mathrm{M}$ belongs as:

$$
\alpha_{M}=\cos ^{-1} \frac{2 \pi r}{\sqrt{S^{2}+4 \pi^{2} r^{2}}}
$$

By analyzing the displacement of point $\mathrm{M}$ on the static coordinate system and its velocity and acceleration, we can calculate the absolute velocity of point $\mathrm{M}$ and the angle between it and the $\mathrm{X}$-axis:

$$
\theta_{M \mathrm{x}}=\cos ^{-1} \frac{\mathrm{v}_{x}}{v_{M}}=\cos ^{-1} \frac{S}{2 \pi \sqrt{\frac{S^{2}}{4 \pi^{2}}+r^{2}}}
$$

Set the helical angle, which is invariable, when point M moves as:

$$
\alpha_{\mathrm{y}}=\frac{\pi}{2}-\theta_{\mathrm{Mx}}=\frac{\pi}{2}-\cos ^{-1} \frac{S}{2 \pi \sqrt{\frac{S^{2}}{4 \pi^{2}}+r^{2}}}
$$

When the helical angle $\alpha_{M}$ of point $\mathrm{M}$ on the diameter of the micro circle is equal to helical angle $\alpha_{\mathrm{y}}$, which is invariable when point $\mathrm{M}$ moves, the test-bed has the most stable run.

\section{Effect of the feeding methods of the screw conveyor on the conveying stability}

The major problem that occurs during the screw conveyor's conveying of the fiber material is the discontinuity and inhomogeneity of feeding, which causes the instability of the filling rate of materials inside the screw conveyor and feeding amount. These phenomena affect the stability of the machine. The designed spring-finger feeder 
in this paper consists of a work bin, a rotating shaft, a spring-finger and a flapper, whose structure is shown in Figure 4 . The rotating shaft is driven by $120-\mathrm{W}$ single-phase speed regulating motor; materials move into the bin along the direction of $\mathrm{A}$, and the spring-finger brings the materials into the helical blade. Flapper 4 prevents the excess materials in the work bin from getting stuck on the spring-finger.

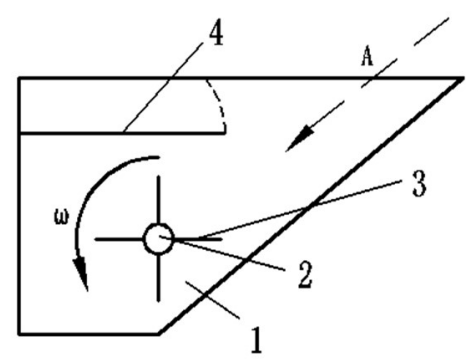

FIGURE 4. Diagram of feeder.

1-bin; 2-rotating shaft; 3-spring-finger; 4-flapper; A-feeding direction.

When the pitch is $250 \mathrm{~mm}$, the RPM is $14 \mathrm{r} / \mathrm{min}$ and the moisture content of rubbed corn straw is $18.237 \%$, the different effects of two feeding ways on the filling rate are shown in Figure 5. The average filling rates of feeding by hand and using the feeding hopper are 0.66 and 0.74 , respectively. When feeding by hand, the filling rate greatly fluctuates. However, when the spring-finger is used to assist in feeding the feeder hopper, the filling rate is controllable, and the device can continually and homogeneously be fed. Therefore, the filling rate inside the screw conveyor fluctuates less. The feeding amount of materials stably increases with time, and it shows a linear relationship of the ideal state, as shown in Figure 6. Because of the axial lag of the material, which is affected by the material characteristics and kinematic parameter of the conveying device, the filling rate cannot reach its ideal state. Thus, we often use the axial lag coefficient and filling coefficient to correct this problem (Wang et al., 2005).

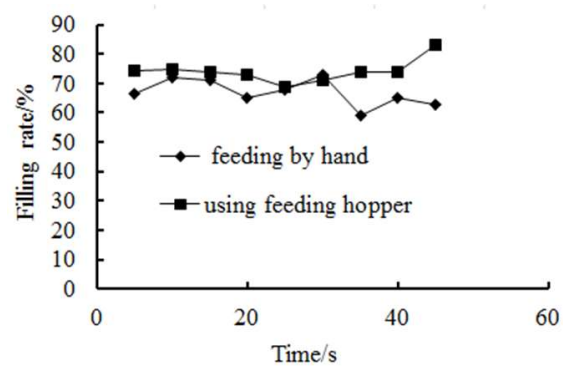

FIGURE 5. Influence of feeding ways on the filling rate.

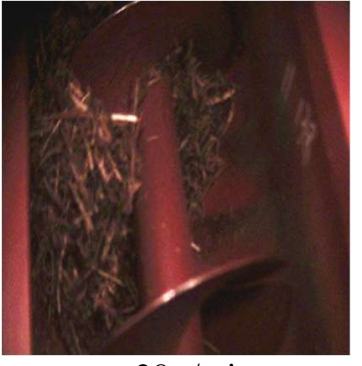

$\mathrm{n}=28 \mathrm{r} / \mathrm{min}$

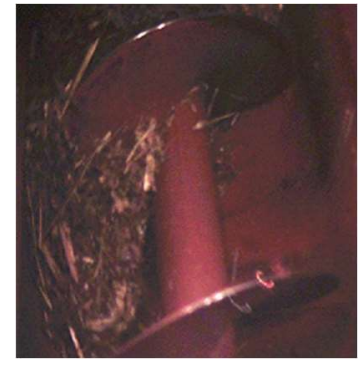

$\mathrm{n}=42 \mathrm{r} / \mathrm{min}$

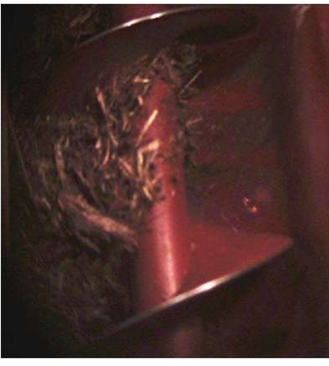

$\mathrm{n}=56 \mathrm{r} / \mathrm{min}$

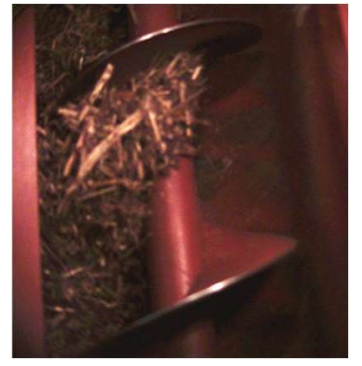

$\mathrm{n}=70 \mathrm{r} / \mathrm{min}$

FIGURE 7a. Movement of materials when the filling rate is less than 0.5 . 


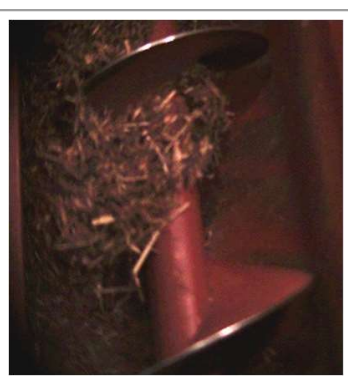

$\mathrm{n}=28 \mathrm{r} / \mathrm{min}$

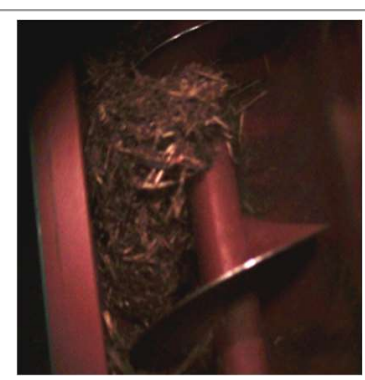

$\mathrm{n}=42 \mathrm{r} / \mathrm{min}$

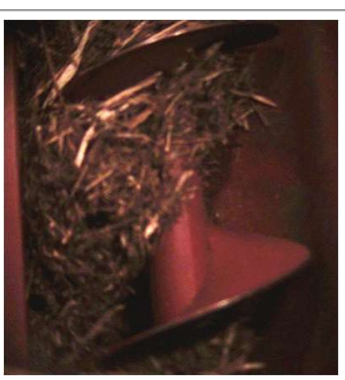

$\mathrm{n}=56 \mathrm{r} / \mathrm{min}$

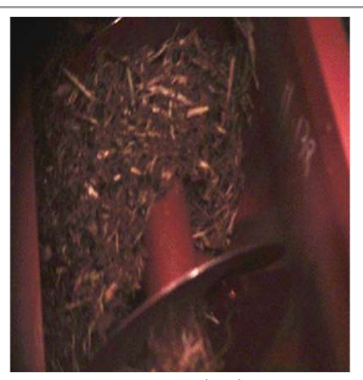

$\mathrm{n}=70 \mathrm{r} / \mathrm{min}$

FIGURE 7b. Movement of materials when the filling rate is more than 0.5 .

When analyzing the flow state of the material, we should first divide the space in a pitch into four sections as shown in Figure 8. I is the absolute conveying section. The materials in this section move axially under the push of the helical blade, gravity, friction between the materials and blade and friction between the materials and surface of the casing. There is not too much relative movement between the materials and blade. When the filling rate is less than 0.5 , the materials more stably move along the axial between sections I and IV. When the rotating speed is $70 \mathrm{r} / \mathrm{min}$, a small part of the materials will move around the axis, as shown in Figure 7a. II and III are the transition sections. When the filling rate is more than 0.5 , the materials in section II will roll over the screw shaft and be conveyed through sections III and IV. During this process, with the effects of the mechanical property and rotational speed, at a higher rotating speed, the materials rotate more freely, which makes the flow rate instable and affects the conveying efficiency, as shown in Figure $7 \mathrm{~b}$. IV is the relative conveying section, whose material movement includes translational motion and rotational motion. A higher filling rate corresponds to more materials in this section. When the revolving speed reaches a certain value, the materials will compress one another, the friction will increase, and the friction between the materials and surface of the casing will increase.
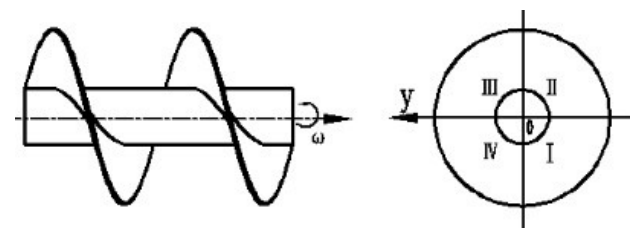

FIGURE. 8 Spiral segmentation image.

\section{Experiment of conveying efficiency}

The conveying efficiency of the screw conveyor is related to the structural parameters of the device, kinematic parameters and characteristic parameters of the materials. The structural parameters of the screw conveyor are fixed values for the test-bed; therefore, it is necessary to discuss the effects of the motion parameters and characteristic parameters of the rubbed corn straw on the conveying efficiency.

When the blade rotates once, it will move forward a pitch. Therefore, the axial speed of the helical blade can be calculated by the following formula:

$$
\mathrm{v}=\frac{n S}{60}
$$

The average used time when conveying the rubbed corn straw for $2500 \mathrm{~mm}$ can be obtained by this experiment to calculate the axial speed of materials $\left(\mathrm{v}_{1}, \mathrm{~m} / \mathrm{s}\right)$. Set the ratio of $\mathrm{v}_{1}$ and $\mathrm{v}$ as the conveying efficiency of screw conveyor, which is also known as the speed utilization coefficient of the screw conveyor, and is calculated as follows:

$$
\frac{\mathrm{v}_{1}}{\mathrm{~V}} \times 100 \%
$$

Figure 9 show the curve of the conveying efficiency of the screw conveyor under 5 different rotating speeds. When the diameter of the screw is $250 \mathrm{~mm}$, the pitch is 250 $\mathrm{mm}$, and the moisture content of rubbed corn straw is $18.237 \%, 39.068 \%$, and $52.203 \%$.

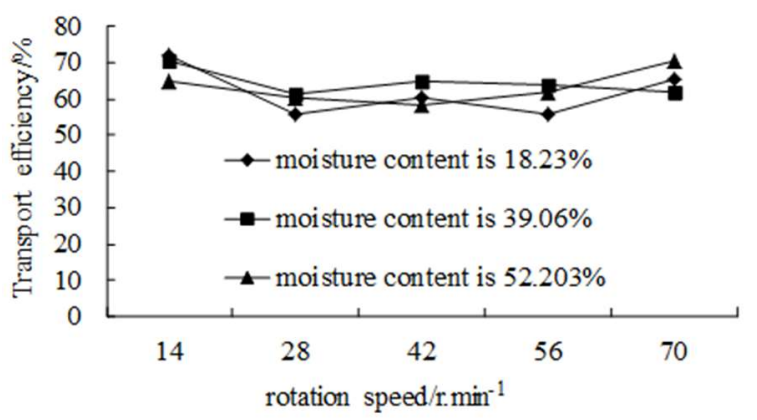

FIGURE 9. Conveying efficiency of screw conveyor.

As shown in Figure 9, with the same moisture content of rubbed corn straw, the conveying efficiency changes with the increase in rotating speed. However, the moisture content of the material and rotating speed of the screw are not proportional to the conveying efficiency. The main reason is as follows:

First, materials with high moisture content have good lubricity, which will reduce the friction among the materials and the friction between straws and surface of the casing, which will reduce the resistance of the conveying and the friction between blades (Du et al., 2018; Fang et al., 2019; Fan et al., 2008). Therefore, it is not easy to bring the materials into section II and move forward in section I of the helical blade, which will improve the conveying efficiency. However, when the materials with high moisture content increase with the rotating speed, the conveying efficiency does not increase much because the stickiness of straw materials increases with the increase in moisture content, which weakens the flow ability and finally affects the conveying efficiency. In addition, for the test-bed of the screw conveyor, the axial speed of any blade with a rotating speed is constant. Therefore, the incensement of conveying efficiency requires the increase in axial speed and minimal circumferential speed. 


\section{CONCLUSIONS}

A test-bed of the screw conveyor was designed, and the movement of the helical blade was analyzed. Then, a mathematical model on the motion trail of any point on the blade was established. The stable running condition of test-bed was obtained: the helical angle of any point on the diameter of the micro circle must be equal to the moving helical angle of that point.

In this study, a spring-finger feeder was designed. Through experiments, it has been validated that the feeder can achieve uniform feeding and overcome the weakness of feeding by hand to strengthen the conveying stability.

The movement of materials inside the screw conveyor was videotaped by a high-speed camera. The conclusion is that the movement of materials in the screw conveyor is relatively steady and rarely affected by the rotation speed when the filling rate is below 0.5 . When the filling rate is higher than 0.5 , the circular movement is enhanced with increasing rotating speed, which affects the working stability of the screw conveyor and reduce the conveying efficiency.

There is no direct connection among the conveying efficiency, moisture content of the materials, and rotation speed of the screw. Therefore, further research is required on the influence factors of the conveying efficiency, such as the pitch of the helical blade and mechanical characteristics of the materials.

\section{ACKNOWLEDGMENTS}

The research was supported by the Inner Mongolia Natural Science Foundation (No. 2020BS05022) and Scientific Research Projects of Inner Mongolia Education Department (NJZY18057).

\section{REFERENCES}

Alma Kurjak (2005) The vertical screw conveyor powder properties and Screw conveyor design. SE-221 00 Lund,Sweden 30(3):586-590.

Bai XH, Li F, Zhang ZL, Wang HL, Cui YJ (2007) Working performance of screw feeding device for straw. Journal of Agricultural Mechanization Research (2):162-164.

Chu TS, Yang ZL, Han LJ (2016) Analysis on satisfied degree and advantage degree of agricultural crop straw feed utilization in China. Transactions of the Chinese Society of Agricultural Engineering 32(22):1-9.

Du XX, Wang CG, Guo WB, Wang HB, Jin M, Liu XD, Li J (2018) Stress relaxtion characteristics and influencing factors of sweet sorghum: experimental study. Bioresourcess 13(4):8761-8774.

Fan L, Wang CG, Wang HB, Zhao GZ, Suo HX (2008)

Study on the compressibility of maize straw rubbed.

Transactions of the Chinese Society for Agricultural Machinery 39(11):76-80.

Feng L, Li TS, Xu KL (2015) Design of screw conveyor device for biomass crushing and molding machine. Forest Engineering 31(3):101-105.
Fang JJ, Li HJ, Wang J,Yang MS, Zong ZY, Zhang Y(2019) Compression and stress relaxation characteristics of alfalfa during rotary compression. Bioresourcess 14(2):3860-3872.

Huang SM (2000) The geometry of a screw conveyor in the feeding mouth effects on transmission performance. Guangdong pulp paper (6):41-43.

Leng BB (2007) A preliminary study on the screw conveyor conveying mechanism based on FLUENT. Master Thesis, Taiyuan University of Technology.

Luo S, Zhang XL, Xu J, Ma K (2013) Structure optimization and performance simulation of screw discontinuous feeding device. Transactions of the Chinese Society of Agricultural Engineering 29(03):250-257.

Ma CL (2018) Improved design of 9RS-2 straw kneading machine. Master Thesis, Gansu Agricultural University.

Owen PJ, Cleary PW (2009) Prediction of screw conveyor performance using the discrete element method (DEM). Powder Technology 19(3):274-288.

Rorres C (2000) The Turn of the screw optimal design of an archmedes screw. Journal of hydraulic engineering 1(4):72-80.

Song ZW, Wang J, Zhu XL, Zhong ZN, Pan Y (2017) Present research status and prospects of the comprehensive utilization of straw resources. Journal of Anhui Agricultural Sciences 45(7):64-66.

Tian YS, Yao ZL, Ouyang SP, Zhao LX, Meng HB, Hou SL (2011) Physical and chemical characterization of biomass crushed straw. Transactions of the Chinese Society for Agricultural Machinery 42(9):124-128.

Wang SS, Mao JR, Liu GW (2005) Mechanism of discharge pulsation of particles feeder and new method of restraining pulsation. Journal of Xi an Jiaotong University 9(11):1199-1202.

Wang MF, Xu Q, Jiang EC, Ren Y, Wu Y, Chen X (2017) Design and pilot test for feeder of biomass shaftless screw continuous pyrolysis device. Transactions of the Chinese Society of Agricultural Engineering 33(4):83-88.

Wulantuya, Wang CG, Qi SH, Yan J, Wang J (2015) Test and analysis of performance of screw conveyor for rubbing and breaking corn straw. Transactions of the Chinese Society of Agricultural Engineering 31(21): 51-59.

Wulantuya, Wang CG, Qi SH, Yan JG, Wang JL (2016) Theoretical model analysis and test of screw conveyor for rubbing and breaking corn straw. Transactions of the Chinese Society of Agricultural Engineering 32(22):18-26.

Zhang XL, Liu YP, Li LH, Tong Z, Yang D, Hou C (2018) Design and performance experiment of multi-segment type auger in process of organic fertilizer production. Transactions of the Chinese Society of Agricultural Engineering 3(3):49-56. 